\title{
Microwave Ablation of Small Hepatic Metastases Using MR Guidance and Monitoring: Clinical Safety and Efficacy
}

This article was published in the following Dove Press journal: Cancer Management and Research

\section{Zhaonan $\mathrm{Li}$ iD* \\ Dechao Jiao* \\ Chaoyan Wang \\ Jing $\mathrm{Li}$ \\ Zaoqu Liu \\ Wenguang Zhang \\ Xinwei Han $(\mathbb{D}$}

Department of Interventional Radiology, First Affiliated Hospital of Zhengzhou University, Zhengzhou, 450000, People's Republic of China

*These authors contributed equally to this work
Correspondence: Xinwei Han Institute of Interventional Radiology, First Affiliated Hospital of Zhengzhou University, No. I Jianshe East Road,

Zhengzhou City, Henan Province, 450000 , People's Republic of China

Tel +86|359258-39|I

Fax +86-37I-66278082

Email 135925839II@I63.com
Background: To evaluate the technical success and clinical safety of magnetic resonance (MR)-guided microwave ablation (MWA) of small hepatic metastases.

Materials and Methods: Institutional review board approval and informed patient consent were obtained. A retrospective analysis of the patient data revealed 50 patients with small hepatic metastases (34 men, 16 women) who underwent MWA under MR guidance and monitoring. After the procedure, the intervention-related complications were classified according to the Common Terminology Criteria for Adverse Events (CTCAE) and Society of Interventional Radiology (SIR) classification system. Furthermore, the overall survival (OS) and local tumor-free survival (LTP) of the patients were analyzed.

Results: The patients who underwent MR-guided MWA achieved technical success. The mean energy, ablation duration per tumor, and procedure duration were $55.3 \pm 9.4 \mathrm{~kJ}, 11.7 \pm$ $5.6 \mathrm{~min}$ and $89.5 \pm 30.9 \mathrm{~min}$, respectively. Most adverse events and complications were CTCAE grade 1 or 2 or SIR classification grade A or B. The 1-, 2-, and 3-year local tumor progression (LTP) rates were $65.9 \%, 31.5 \%$ and $18.5 \%$, respectively, with a mean LTP of 19.216 months (95\% CI: 16.208, 22.224); and the 1-, 2- and 3-year overall survival (OS) rates were $81.8 \%, 60.8 \%$ and $44.7 \%$, respectively, with a mean OS of 26.378 months $(95 \%$ CI: $23.485,29.270)$. Multivariate Cox's regression analysis further illustrated that tumor location (challenging locations vs ordinary locations) and the anesthesia (general anesthesia VS local anesthesia) were important factors affecting LTP and OS.

Conclusion: MR-guided MWA can successfully treat small hepatic metastases with potentially favorable safety and technical efficacy.

Keywords: microwave ablation, magnetic resonance imaging, liver tumors, tumor ablation, hepatic malignancies

\section{Background}

Image-guided thermal ablation has become a valuable therapeutic approach for the treatment of hepatic malignancies and is included in several guidelines. ${ }^{1,2}$ Of note, radiofrequency ablation (RFA) and microwave ablation (MWA) are the most commonly used thermal ablation methods for hepatic malignancies. ${ }^{3}$ In comparison with RFA, MWA can bring the target lesion to a higher temperature in a shorter period of time, which actually allows a larger ablation zone to be produced, Thus reducing the procedure duration. ${ }^{4}$ In addition to the device itself, the use of a reasonable and effective imaging modality is also vital for successful and safe ablation. Currently, ultrasound and computed tomography (CT) are the most 
frequently used modalities. However, ultrasound-guided thermal ablation has difficulty overcoming the formation of bubbles and poor image contrast during the procedure. Although CT can provide accurate imaging, it is difficult to distinguish the boundary between the residual tumor and the ablation area after treatment. ${ }^{5}$ Because MRI provides the most reliable visualization of target tumors, superior soft tissue contrast, and the ability to perform multiplane imaging, MR-guided MWA has been suggested to be an effective solution to overcome the above disadvantages. $^{6-8}$

Therefore, the purpose of this study was to investigate the feasibility of MR-guided percutaneous ablation in patients with small hepatic metastases and to assess the immediate technical success, safety and outcome.

\section{Materials and Methods}

\section{Patients}

From November 2016 to July 2018, we retrospectively enrolled 50 patients in our institution who received MRguided MWA of secondary hepatic malignancies (52.5 \pm 13.2 years; range $36-71$ years). The retrospective study was approved by the institutional review board. The study protocol complied with the Helsinki Declaration. Written informed consent was obtained from all patients prior to treatment. All patients received chemotherapy due to tumor metastasis before MWA. The response to chemotherapy was divided into partial response (PR), stable disease (SD), and disease progression (PD). The patient characteristics in (Table 1). The detailed inclusion and exclusion criteria are listed in (Table 2).

\section{Equipment}

In this study, the MR-compatible MWA apparatus (2450 $\mathrm{MHz}, \mathrm{ECO}$ Medical Instrument Co., Ltd. Nanjing, China) and a microwave antenna (ECO-100AI13, $1.8 \mathrm{~mm}, 15 \mathrm{~cm}$, Co., Ltd. Nanjing, China) were used. Respiratory and ECG gating sensors (Invivo, Orlando, USA) were placed around the chest wall and finger, respectively. The MR signal was received by a Torso body coil with two rectangular square holes to facilitate interventional procedures. MWA was guided by a 3.0 $\mathrm{T}$ dual gradient MR scanner (Magnetom Verio 3.0T scanner, Siemens Healthineers, Germany) with a closed bore (inner-diameter, $70 \mathrm{~cm}$ ). The MR scanning sequences and parameters used in our study have been listed below:
Table I Patient Characteristics

\begin{tabular}{|c|c|c|}
\hline Characteristics & Patients $(n=50)$ & Percentage (\%) \\
\hline Age * & $52.5 \pm \mid 3.2(36-7 \mid)$ & \\
\hline$\geqslant 60$ & 21 & 42 \\
\hline$<60$ & 29 & 58 \\
\hline \multicolumn{3}{|l|}{ Sex } \\
\hline Male & 34 & 68 \\
\hline Female & 16 & 32 \\
\hline \multicolumn{3}{|l|}{ ECOG performance status } \\
\hline 0 & 35 & 70 \\
\hline 1 & 15 & 30 \\
\hline \multicolumn{3}{|l|}{ Diagnosis } \\
\hline $\begin{array}{l}\text { Hepatic metastasis of rectal } \\
\text { carcinoma }\end{array}$ & 21 & 42 \\
\hline $\begin{array}{l}\text { Hepatic metastasis of colonic } \\
\text { carcinoma }\end{array}$ & 19 & 38 \\
\hline $\begin{array}{l}\text { Hepatic metastasis of gastric } \\
\text { carcinoma }\end{array}$ & 6 & 12 \\
\hline $\begin{array}{l}\text { Hepatic metastasis of } \\
\text { cholangiocarcinoma }\end{array}$ & 4 & 8 \\
\hline \multicolumn{3}{|l|}{$\begin{array}{l}\text { Response to chemotherapy } \\
\text { previous to MWA }\end{array}$} \\
\hline Partial remission (PR) & 32 & 64 \\
\hline Stable disease (SD) & 6 & 12 \\
\hline Progressive disease (PD) & 12 & 24 \\
\hline \multicolumn{3}{|l|}{ Child-Pugh grade } \\
\hline A & 33 & 66 \\
\hline B & 17 & 34 \\
\hline \multicolumn{3}{|l|}{ Tumor diameter } \\
\hline $3 \geqslant \mathrm{~cm},<5 \mathrm{~cm}$ & 28 & 56 \\
\hline$<3 \mathrm{~cm}$ & 22 & 44 \\
\hline \multicolumn{3}{|l|}{ Tumor location } \\
\hline Challenging locations & 17 & 34 \\
\hline Other parts & 33 & 66 \\
\hline \multicolumn{3}{|l|}{ Anesthesia } \\
\hline General anesthesia & 15 & 30 \\
\hline Local anesthesia & 35 & 70 \\
\hline \multicolumn{3}{|l|}{ Number of lesion } \\
\hline Single (I) & 26 & 52 \\
\hline 2-3 lesions & 24 & 48 \\
\hline
\end{tabular}

Notes: ECOG, Eastern Cooperative Oncology Group; data are numbers of patients. *Data are mean \pm standard deviation. Challenging locations (hepatic dome, close to the heart/diaphragm/hepatic hilum).

Abbreviations: GA, general anesthesia; LA, local anesthesia.

1. T2WI (Transverse section, T2 Haste, 16 s) singleshot half Fourier haste breath holding sequence: repetition time (TR) $1000 \mathrm{~ms}$, echo time (TE) 106 $\mathrm{ms}$, flip angle (FA) $180^{\circ}$, slice thickness (ST) 4.5 $\mathrm{mm}$, field of view (FOV) $137 \times 256$, Band width (Hz/pixel) 781. 
Table 2 Inclusion and Exclusion Criteria

\begin{tabular}{|l|l|}
\hline Inclusion Criteria & Exclusion Criteria \\
\hline I Age range: $18-75$ years & Age $<18$ or $>75$ years \\
\hline 2 Child-Pugh grade A or B & Child-Pugh grade C \\
\hline 3 BCLC grades are A or B & BCLC grades are C \\
\hline 4 ECOG score $\leqq 2$ & ECOG score $>2$ \\
\hline 4 Liver lesions $\leq 3$ & The liver lesions number $>3$ \\
\hline 5 Single tumor diameter $<5 \mathrm{~cm}$ & Single tumor diameter $\geqq 5$ \\
\hline $\begin{array}{l}6 \text { The expected survival time }>3 \\
\text { months }\end{array}$ & $\begin{array}{l}\text { The expected survival time } \leq 3 \\
\text { months }\end{array}$ \\
\hline 7 No portal vein thrombus & Portal vein thrombus \\
\hline 9 PLT $>40 \times 109 / L$ or PT $\leq 25 \mathrm{~s}$ & PLT $\leq 40 \times 109 / \mathrm{L}$ or PT $>25 \mathrm{~s}$ \\
\hline
\end{tabular}

Abbreviations: EASL, European Association for the Study of the Liver; ECOG Eastern Cooperative Oncology Group; PLT, platelet; PT, prothrombin time.

2. T1WI (Transverse section, T1 Vibe, $16 \mathrm{~s}$ ) gradient echo volume interpolation body part inspection sequence: TR $4.56 \mathrm{~ms}$, TE $1.93 \mathrm{~ms}$, FA $9.0^{\circ}$, ST $3.3 \mathrm{~mm}$, FOV $230 \times 288$, Band width $(\mathrm{Hz} /$ pixel $)$ 400.

3. T2WI (Sagittal section) single-shot half Fourier haste breath holding sequence: TR $1000 \mathrm{~ms}$, TE $106 \mathrm{~ms}$, FA $180^{\circ}$, ST $4.0 \mathrm{~mm}$, FOV $165 \times 256$, Band width (Hz/pixel) 781.

4. T1WI (Coronal section) gradient echo volume interpolation body part inspection sequence: TR $6.11 \mathrm{~ms}$, TE $2.46 \mathrm{~ms}$, FA $9.0^{\circ}$, ST $3.0 \mathrm{~mm}$, FOV $179 \times 256$, Band width (Hz/pixel) 410.

\section{Ablation Procedure Protocol}

The patient's position was determined according to the preoperative puncture plan on CT/MR. Routine electrocardiogram and oxygen saturation monitoring (Invivo, Orlando, USA) and an ECO-100E MR-compatible MWA system were placed at a distance of 3 meters next to the MR-compatible operating table (For patients under general anesthesia). Dexmedetomidine $(0.5 \mu \mathrm{g} / \mathrm{kg})$ and tropisetron $(8 \mathrm{mg})$ were injected intravenously $10 \mathrm{~min}$ before the procedure, and Diloxin ( $5 \mathrm{mg}$ ) was injected intravenously 5 min before ablation. All procedures were performed by an alternating team of two trained interventional radiologists with 6-10 years of experience in ablation procedures. After being marked on the body surface with a cod liver oil capsule matrix, the puncture site was sterilized, and $2 \%$ lidocaine was used for local anesthesia. Under the guidance of MR, the microwave antenna was inserted into the center of the tumor. The antenna insertion process required multiple T1 (Vibe, $16 \mathrm{~s}$ ) sequences to confirm the correct position and angulation of the applicator. After confirming that the tip of the antenna was $0.5-1 \mathrm{~cm}$ beyond the distal tumor, the transmitter was turned on for ablation. Of note, the tumor at each site was ablated with $45-70 \mathrm{~W}$ for $5-18$ mins. After the ablation was complete, the MWA was powered off, and unenhanced MRI scans (T2 Haste, 16 s) and T1 (Vibe, $16 \mathrm{~s}$ ) were acquired to assess the immediate treatment results and complications and ensure that the ablation area covered the entire lesion and extended beyond the margin by $0.5-1 \mathrm{~cm}$. If the ablative zone, which was considered the $\mathrm{T} 1$ hyperintense or T2 hypointense area, does not cover the target tumor, then the antenna was repositioned, and the ablation continued. Reexamination of enhanced magnetic resonance on the second day after procedure (Detailed information can be seen in Figures 1 and 2).

\section{Evaluation of Tumor Response}

The ablation evaluation standards were the modified response evaluation criteria in solid tumors (mRECIST; 2020 edition). Adverse events and complications after treatment are classified according to the Common Terminology Criteria for Adverse Events (CTCAE) of the National Cancer Institute. Local tumor progression (LTP) was defined as detection of nodular enhancement in the adjacent ablation area during follow-up.

\section{Follow-Up}

All patients received postclinical care. If the abdominal ultrasound, routine blood, liver and kidney function tests and physical condition were appropriate on the following day, the patients could be discharged. Liver MR was reviewed 1 month after the procedure and every 3-4 months thereafter. For the patients who developed LTP, further ablation was offered. Surgical resection was performed for the lesions that could not be completely ablated under MR guidance. For the patients with LTP who could not receive ablation or resection due to the location or other reasons, systemic chemotherapy was administered whenever possible. The patients were followed up to April 2020 or until death. 



Figure I A 62-year-old patient with metastasis $(28 \mathrm{~mm}$ ) of colonic carcinoma. (A and D) Preinterventional planning imaging and MR-guided targeting (Red arrow). (B) The image shows the precise positioning of the antenna into and ablation of the lesion on the transverse position. (C and $\mathbf{E})$ High-signal target tumor lesions are clearly visible in the unenhanced T2 sequence. (F; dashed circle) After one day of precise ablation, enhanced magnetic resonance reexamination found the signal of the target lesion changed significantly, forming a round-shaped low-signal target sign.


Figure 2 Hepatic metastasis of colonic carcinoma in the hepatic dome of a 53-year-old man treated with MR-guided MWA. (A) The metastatic nodules near the edge of the heart (red arrow) is $17 \mathrm{~mm}$ in diameter and appears as hyper-intensity on T2-weighted transverse images before MWA. (B-D) The trajectory of the tilting puncture were adjusted gradually for the lesion target under the guidance of coronal TIWI and the image shows precise insertion of the antenna into the target. (E) After one day of MWA, enhanced magnetic resonance reexamination found the treatment border covered the lesion completely as hyperintensity on TIWI (dashed circle) without penetrating the diaphragm and pericardium. (F) The lesion (red arrow) is completely ablated without a diaphragm injury at I-month follow-up. 
Table 3 Adverse Events and Complications

\begin{tabular}{|c|c|c|c|}
\hline \multirow[t]{2}{*}{ Categories } & \multicolumn{2}{|c|}{ Grades } & \multirow[t]{2}{*}{$\mathbf{N}(\%)$} \\
\hline & \multicolumn{2}{|c|}{ CTCAE/SIR } & \\
\hline \multicolumn{4}{|l|}{ Adverse events } \\
\hline Fever, maximum $38^{\circ} \mathrm{C}$, no treatment & I & A & $12(24)$ \\
\hline Fever, $>38^{\circ} \mathrm{C}$ & 2 & B & $8(16)$ \\
\hline Nausea or vomiting & I & B & $4(8)$ \\
\hline Asymptomatic right pleural effusion & I & A & $5(10)$ \\
\hline Mild pain, requiring nonopioid oral analgesic treatment & 2 & B & $16(32)$ \\
\hline Moderate pain, requiring opioid oral analgesic treatment & 2 & B & $21(42)$ \\
\hline Mild liver dysfunction, requiring conservative treatment & 2 & B & $19(38)$ \\
\hline Total bilirubin elevation, transient & 2 & B & $15(30)$ \\
\hline Hypoalbuminemia, transient & 1 & A & $5(10)$ \\
\hline Liver abscess & 2 & B & $2(4)$ \\
\hline \multicolumn{4}{|l|}{ Complications } \\
\hline Pleural effusion & 2 & C & I (2) \\
\hline Subcapsular liver hemorrhage & 3 & D & $2(4)$ \\
\hline
\end{tabular}

Notes: National Cancer Institute Common Terminology Criteria for Adverse Event (CTCAE version 4.03), uses Grades I through 5 to refer to the severity of the adverse events, based on general guidelines: Grade I mild - asymptomatic or mild symptoms, clinical or diagnostic observations only, intervention not indicated; Grade 2 moderate minimal, local or noninvasive intervention indicated; Grade 3 severe - medically significant but not immediately life-threatening, hospitalization or prolongation of hospitalization indicated, disabling; Grade 4 life-threatening - urgent intervention indicated; Grade 5 death - related to adverse event. Society of Interventional Radiology (SIR) classification system for Complications by Outcome describes minor complications (Grade A - no therapy, no consequence; Grade B - nominal therapy, no consequence) and major complications (Grade C - require therapy, minor hospitalization; Grade D - require major therapy, unplanned increase in level of care, prolonged hospitalization; Grade E - permanent adverse sequelae; Grade F - death). Data are numbers of events. Data in parentheses are percentages.

\section{Statistical Analysis}

Statistical analyses were performed with SPSS version 22.0 software (SPSS Inc., Chicago, IL). Continuous variables are shown as the mean \pm standard deviation, and categorical data are reported as numbers with percentages. The Kaplan-Meier survival curves were used for survival analysis. Univariate and multivariate Cox's proportional hazards regression analyses were used to predict prognostic factors of LTP and OS. A $\mathrm{P}<0.05$ was considered for significant differences.

\section{Results}

\section{Patient Characteristics}

The mean age of the patients was $52.5 \pm 13.2$ years (range, $36-71$ years). Of the 50 patients, 29 (58\%) were 60 years old or younger, $34(68 \%)$ were male. The number of liver metastases due to colonic carcinoma, rectal carcinoma, gastric carcinoma, and cholangiocarcinoma was 19 $(38 \%), 11(22 \%), 6(12 \%)$ and $4(8 \%)$, respectively. Among the 50 patients, $22(44 \%)$ had tumors $<3 \mathrm{~cm}$ i n diameter. And, 33 (66\%) patients were considered ChildPugh A, while 22 (44\%) were considered Child-Pugh B. In addition, 15 cases were completed under general anesthesia and the number of patients with a single metastasis accounted for half of the total number. The mean energy, ablation duration per tumor, and procedure duration were $55.3 \pm 9.4 \mathrm{~kJ}, 11.7 \pm 5.6 \mathrm{~min}$ and $89.5 \pm 30.9$ min, respectively.

\section{Complications and Side Effects}

Postoperative pain and fever (without treatment) were the most common adverse events after treatment (Table 3). With three exceptions, Most adverse events and complications were CTCAE grade 1 or 2 or SIR classification grade A or B (no or nominal treatment, no consequences). Of the exceptions, two patients developed hepatic subcapsular hemorrhage and required interventional embolization, and another patient developed massive right pleural effusion requiring thoracic drainage.

\section{OS and LTP}

After MR-guided MWA procedure, the 1-, 2-, and 3-year LTP rates were $65.9 \%, 31.5 \%$ and $18.5 \%$, respectively, with a mean LTP of 19.216 months (95\% CI: 16.208, 22.224) (Figure 3A); and the 1-, 2- and 3-year overall survival (OS) rates were $81.8 \%, 60.8 \%$ and $44.7 \%$, respectively, with a mean OS of 26.378 months (95\% CI: 23.485 , 29.270) (Figure 3B). Kaplan-Meier LTP and OS with 



Figure 3 Kaplan-Meier local tumor progression (LTP) and overall survival (OS) with hepatic metastases; (A) mean LTP was 19.216 months (95\% Cl: 16.208, 22.224); (B) mean OS was 26.378 months (95\% Cl: $23.485,29.270)$. The I-, 2-, and 3-year LTP rates with hepatic malignant tumors were $65.9 \%, 31.5 \%$ and I8.5\%, respectively; and the I-, 2- and 3 -year OS rates were $81.8 \%, 60.8 \%$ and $44.7 \%$, respectively.
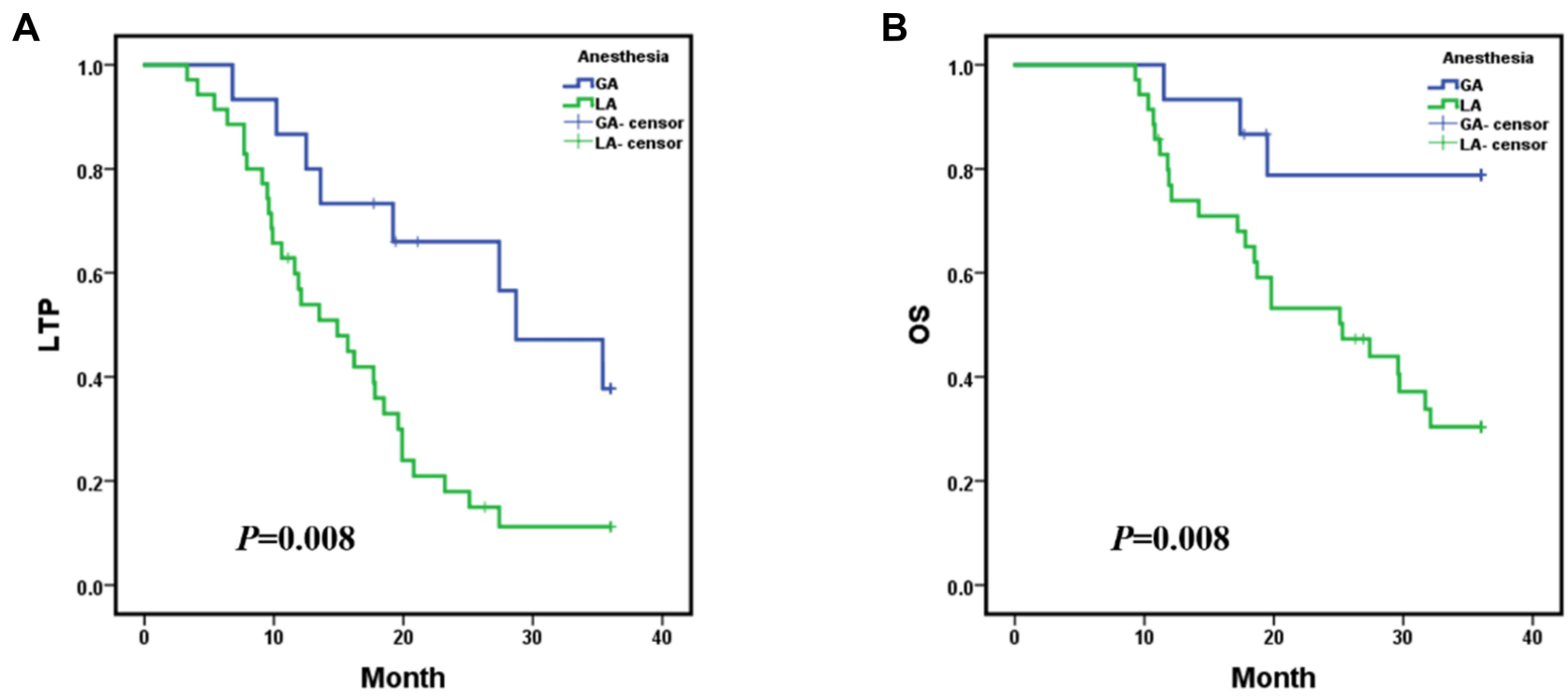

Figure 4 Kaplan-Meier local tumor progression (LTP) and overall survival (OS) with microwave ablation (MWA) under general anesthesia (GA) versus MWA under local anesthesia (LA) management; (A) mean LTP was 26.486 months ( $95 \% \mathrm{Cl}: 20.976,31.995)$ in procedure under GA versus I6.285 months (95\% Cl: I3.189, I9.38I) in the LA $(p=0.008$, Log rank test); (B) mean OS was 31.827 months $(95 \% \mathrm{Cl}: 27.573,36.08 \mathrm{I})$ in the procedure under GA versus 24.080 months $(95 \% \mathrm{Cl}$ : $20.65 \mathrm{I}, 27.508)$ in the LA management ( $p=0.008$, Log rank test). The I-, 2-, and 3-year LTP rates with MWA under GA were $86.7 \%, 66.0 \%$ and $37.7 \%$, respectively; and the I-, 2- and 3-year OS rates were $93.3 \%, 78.8 \%$ and $78.8 \%$, respectively. The I-, 2-, and 3-year LTP rates with MWA under LA were $56.9 \%$, $18.0 \%$ and II.2\%, respectively; and the I-, 2- and 3-year OS rates were $76.8 \%, 53.2 \%$ and $30.4 \%$, respectively.

MWA under general anesthesia (GA) versus local anesthesia (LA) management. Mean LTP was 26.486 months (95\% CI: 20.976, 31.995) in procedure under GA versus 16.285 months $(95 \% \mathrm{CI}: 13.189,19.381)$ in LA $(p=$ 0.008, Log rank test) (Figure 4A). Mean OS was 31.827 months (95\% CI: 27.573, 36.081) in the procedure under GA versus 24.080 months (95\% CI: 20.651, 27.508) in the
LA management ( $p=0.008$, Log rank test) (Figure 4B). The 1-, 2-, and 3-year LTP rates with MWA under GA were $86.7 \%, 66.0 \%$ and $37.7 \%$, respectively; and the $1-, 2-$ and 3-year OS rates were $93.3 \%, 78.8 \%$ and $78.8 \%$, respectively. The 1-, 2-, and 3-year LTP rates with MWA under LA were $56.9 \%, 18.0 \%$ and $11.2 \%$, respectively; and the 1-, 2- and 3-year OS rates were $76.8 \%, 53.2 \%$ 
A



B

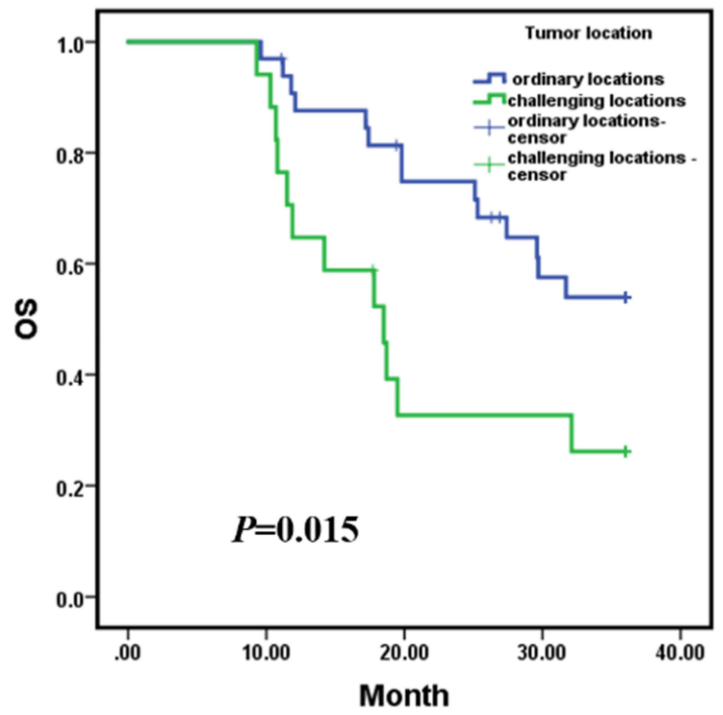

Figure 5 Kaplan-Meier local tumor progression (LTP) and overall survival (OS) with tumor in ordinary locations versus tumor in challenging locations; (A) mean LTP was 21.641 months $(95 \% \mathrm{Cl}$ : 18.179, 25.102) in ordinary locations versus 14.761 months $(95 \% \mathrm{Cl}$ : 9.633, 19.889) in the challenging locations group $(p=0.033$, Log rank test); $(\mathbf{B})$ mean OS was 29.073 months $(95 \% \mathrm{Cl}: 25.926,32.219)$ in the tumors with ordinary locations versus 21.008 months $(95 \% \mathrm{Cl}$ : $15.954,26.063)$ in the challenging locations $(p=$ 0.015 , Log rank test). The I-, 2-, and 3-year LTP rates with tumor in ordinary locations were $81.7 \%$, $36.4 \%$ and $20.5 \%$, respectively; and the I-, 2- and 3-year OS rates were $90.7 \%, 81.3 \%$ and $53.9 \%$, respectively. The I-, 2-, and 3-year LTP rates in tumor with challenging locations were $35.3 \%, 23.5 \%$ and I5.7\%, respectively; and the I-, 2- and 3 -year OS rates were $64.7 \%, 32.7 \%$ and $26.1 \%$, respectively.

and $30.4 \%$, respectively. Additionally, under the MRguided MWA procedure, we compared the LTP and OS of the tumor at the ordinary locations and the challenging locations. The mean LTP was 21.641 months (95\% CI: $18.179,25.102)$ in ordinary locations versus 14.761 months (95\% CI: 9.633, 19.889) in the challenging locations group ( $p=0.033$, Log rank test) (Figure 5A). The mean OS was 29.073 months (95\% CI: 25.926, 32.219) in the tumor with ordinary locations versus 21.008 months (95\% CI: $15.954,26.063)$ in the challenging locations ( $p=$ 0.015, Log rank test) (Figure 5B). The 1-, 2-, and 3-year LTP rates with tumor in ordinary locations were $81.7 \%$, $36.4 \%$ and $20.5 \%$, respectively; and the 1-, 2- and 3-year OS rates were $90.7 \%, 81.3 \%$ and $53.9 \%$, respectively. The 1-, 2-, and 3-year LTP rates in tumor with challenging locations were $35.3 \%, 23.5 \%$ and $15.7 \%$, respectively; and the 1-, 2- and 3-year OS rates were $64.7 \%, 32.7 \%$ and $26.1 \%$, respectively.

\section{Factors Affecting OS and LTP}

Univariate Cox's proportional hazard regression indicated that tumor in ordinary locations, general anesthesia, and single tumor were correlated with longer LTP $(P=0.038$, $P=0.011$ and $P=0.003$, respectively $)$ and $\mathrm{OS}(P=0.019$, $P=0.015$ and $P=0.032$, respectively). In addition, multivariate Cox regression indicated that the tumor diameter
$(3 \mathrm{~cm} \geq,<5 \mathrm{~cm})$ and the number of lesion (2-3 lesions) was an independent factor predicting a shorter LTP (both $P<0.05$, respectively). Furthermore, multivariate Cox regression revealed that the tumor in ordinary locations and general anesthesia were both independently predicted to have a longer LTP and OS in patients with liver metastases (both $\mathrm{P}<0.05$, respectively). (Table 4)

\section{Discussion}

A pathological analysis of 225 patients with HCC confirmed that US, CT and MRI had sensitivities of $46 \%, 65 \%$ and $72 \%$, respectively, in detecting lesions and $21 \%, 40 \%$ and $47 \%$, respectively, in detecting small $\mathrm{HCC}(<2 \mathrm{~cm}){ }^{9}$ The smaller the diameter of the tumor was, the lower the detection ability of the imaging modality. MR-guided ablation has the incomparable advantages of ordinary CT and ultrasound, such as no ionizing radiation, no gas artifact interference and high tissue resolution, and can show lesions that are difficult to observe on CT and US. This reduces the risk of incomplete ablation or adverse events. Clasen et al ${ }^{10}$ pointed out that compared with CT-guided procedures, MR-guided ablation has a higher primary effectiveness rate.

The study by Rempp et al ${ }^{11}$ observed that all tumor progression occurred at the edge of the ablation zone, and previous research has repeatedly dealt with the importance 
Table 4 Factors Affecting LTP and OS

\begin{tabular}{|c|c|c|c|c|c|c|c|c|}
\hline \multirow{3}{*}{$\begin{array}{l}\text { Parameters } \\
\text { Univariate Cox's regression }\end{array}$} & \multirow{4}{*}{$\begin{array}{l}\text { LTP } \\
\text { HR } \\
\\
\\
\\
\end{array}$} & \multirow{2}{*}{\multicolumn{2}{|c|}{$\begin{array}{l}95 \% \mathrm{Cl} \\
\text { Lower Higher }\end{array}$}} & \multirow{4}{*}{$\begin{array}{l}\mathbf{P} \\
0.455\end{array}$} & \multirow{4}{*}{$\begin{array}{l}\text { OS } \\
\text { HR } \\
\\
1.073\end{array}$} & \multirow{2}{*}{\multicolumn{2}{|c|}{$\begin{array}{l}95 \% \mathrm{Cl} \\
\text { Lower Higher }\end{array}$}} & \multirow[t]{3}{*}{$P$} \\
\hline & & & & & & & & \\
\hline & & & & & & & & \\
\hline Age $(>60$ vs $\leq 60)$ & & 0.379 & 1.513 & & & 0.492 & 2.337 & 0.860 \\
\hline Child-Pugh grade (A vs B) & 1.281 & 0.662 & 2.480 & 0.462 & 1.411 & 0.637 & 3.129 & 0.396 \\
\hline Tumor diameter $(3 \geqslant,<5$ vs $<3 \mathrm{~cm})$ & 6.000 & 0.317 & 1.135 & 0.116 & 0.618 & 0.285 & 1.337 & 0.222 \\
\hline $\begin{array}{l}\text { Tumor location (challenging locations vs ordinary } \\
\text { locations) }\end{array}$ & 3.399 & 1.040 & 3.962 & 0.038 & 2.546 & 1.169 & 5.546 & 0.019 \\
\hline Anesthesia (GA VS LA) & 2.789 & 1.262 & 6.161 & 0.011 & 4.452 & 1.332 & 14.877 & 0.015 \\
\hline Number of lesion (single VS 2-3 lesions) & 2.717 & 1.413 & 5.226 & 0.003 & 2.379 & 1.076 & 5.259 & 0.032 \\
\hline Multivariate Cox's regression & & & & & & & & \\
\hline Age $(>60$ vs $\leq 60)$ & 0.801 & 0.389 & 1.649 & 0.547 & 1.480 & 0.657 & 3.333 & 0.344 \\
\hline Child-Pugh grade (A vs $B$ ) & 1.842 & 0.879 & 3.861 & 0.106 & 2.213 & 0.904 & 5.417 & 0.082 \\
\hline Tumor diameter $(3 \geqslant,<5$ vs $<3 \mathrm{~cm})$ & 0.482 & 0.242 & 0.962 & 0.039 & 0.516 & 0.227 & 1.173 & 0.114 \\
\hline $\begin{array}{l}\text { Tumor location (challenging locations vs ordinary } \\
\text { locations) }\end{array}$ & 2.278 & 1.086 & 4.779 & 0.029 & 2.356 & 1.030 & 5.391 & 0.042 \\
\hline Anesthesia (GA VS LA) & 2.845 & 1.218 & 6.644 & 0.016 & 5.426 & 1.519 & 19.378 & 0.009 \\
\hline Number of lesion (single VS 2-3 lesions) & 2.201 & 1.099 & 4.410 & 0.026 & 1.628 & 0.676 & 3.925 & 0.277 \\
\hline
\end{tabular}

Notes: Challenging locations (hepatic dome, close to the heart/diaphragm/hepatic hilum). Bold values indicate $P<0.05$.

Abbreviations: GA, general anesthesia; LA, local anesthesia; HR, hazard ratio; Cl, confidence interval; LTP, local tumor progression.

of the safety margin of tumor ablation. ${ }^{12-14}$ Although the mean safety margin based on the measured tumor diameter and ablation zone seemed to be sufficient, insufficient focal margins were detected in various cases, which may be the cause of local progression. Recently, MR-guided MWA has been commonly used as a minimally invasive therapy for the treatment of primary and metastatic liver malignancies. ${ }^{6,8,15,16}$ In fact, the MR-guided method could ensure precise insertion of the applicator into the target tissue and enable monitoring and controlling the degree of tissue coagulation to confirm that the tumor has been completely destroyed as well as reduce the impact on normal liver tissue and thermal damage to adjacent structures. ${ }^{7,10}$ The characteristic of coagulative necrosis during MR-guided ablation is that the signal intensity on T2WI decreases while the signal intensity on T1WI increases. Actually, the signal strength of the tumor is closely related to the water content of the tissue. The ablation process significantly reduces the water content in the tissue, contributing to a reduction in both $\mathrm{T} 1$ and $\mathrm{T} 2$ values, and the lesions appear hyperintense on T1WI and hypointense on T2WI with clear, well-defined edges. $^{7,17}$ Research by Chen et $\mathrm{al}^{18}$ found that MRguided ablation can only be considered completely necrotic when the lesion is perfectly covered by the ablation zone, that is. Appears with high-intensity edges on T1WI and low-intensity edges on T2WI (including a safe ablation margin of more than 5-10 mm). Otherwise, the electrode was repositioned into the residual lesion, and additional MWA was performed. In this retrospective study, the technical success rate of MR-guided ablation for small hepatic malignancy was $100 \%$, which is consistent with the rate in Weiss's research. ${ }^{19}$

In this research, univariate Cox's proportional hazard regression indicated that tumor in ordinary locations, general anesthesia, and single tumor were correlated with longer LTP $(P=0.038, P=0.011$ and $P=0.003$, respectively) and $\operatorname{OS}(P=0.019, P=0.015$ and $P=0.032$, respectively). Additionally, multivariate Cox's regression revealed that the tumor in ordinary locations and general anesthesia were both independently predicted to have a longer LTP and OS in patients with liver metastases (both $\mathrm{P}<0.05$, respectively). Percutaneous MR-guided MWA procedures have traditionally been performed under local anesthesia (LA) and sedation. However, pain control is often difficult to manage, especially in some cases when the tumor is large or in a specific location, such as near the abdominal wall or close to the hepatic dome. If intraoperative pain is not well controlled, interventional procedure will inevitably be affected. Additionally, LA may affect respiratory activity and cause complications related to anesthesia, such as 
respiratory depression or respiratory arrest. Furthermore, due to the claustrophobic environment and intense noise in the MRI room, some patients have to experienced severe anxiety and insecurity, preventing the completion of the operation, which also leads to an insufficient tumor ablation area. In fact, there may be significant differences in the rate of local recurrence between patients who have reached a sufficient ablation area and those who have not. Therefore, it is essential to ensure sufficient tumor ablation during MRI-guided MWA procedure to optimize the treatment effect.

Regretfully, the real-time MR thermometry technique was not used in this study due to software limitations. Moreover, there are several limitations of our research. First, the closed-bore size and loud equipment noise may negatively impact the treatment experience of patients under local anesthesia. Therefore, effective comfort and companionship are most likely necessary for patients undergoing MR-guided procedures. Second, this is a single-center retrospective study involving a small number of cases, which may lead to biased results. Thus, further studies need to be combined with prospective multicenter studies and extend the follow-up period to reduce the risk of bias. Finally, the duration of MRguided MWA is relatively longer than conventional CTguided treatment. However, we have already used more optimized sequences to reduce the duration of the procedures and improve treatment efficiency.

\section{Conclusion}

In summary, we have shown that MWA for small hepatic metastases can be performed under MR guidance and monitoring. The procedure was considered feasible and effective, and the complications were controllable.

\section{Abbreviations}

MR, Magnetic Resonance; MWA, Microwave ablation; RFA, Radiofrequency ablation; CTCAE, Terminology Criteria for Adverse Events; mRECIST, Modified Response Evaluation Criteria in Solid Tumors; LTP, Local tumor progression; OS, Overall survival; SIR, Society of Interventional Radiology.

\section{Data Sharing Statement}

The datasets used and/or analyzed during the current study are available from the corresponding author on reasonable request.

\section{Ethics Approval and Consent to Participate}

This study protocol was approved by the institutional review board of the First Affiliated Hospital of Zhengzhou University. The study was conducted in accordance with the ethical principles laid down in the Declaration of Helsinki. Written informed consent was obtained from all patients before treatment.

\section{Consent for Publication}

Not applicable.

\section{Acknowledgments}

We would like to thank the patients and all employees of the First Affiliated Hospital of Zhengzhou University for interventional radiology. Thanks to Ms. Chen Xinyue from CT collaboration NE Asia, Siemens Healthcare, Beijing, China, contributed strong technical support as well as language polish to this article.

\section{Funding}

The present study was supported by the Science and technology project of the Henan Province (2017-2019) (172102310388) and the Key Scientific Research Projects of the Higher Education Institutions in the Henan Province (20A320024). This work was supported by the Provincial and ministerial youth projects and the Henan Medical Science and Technology Public Relations Program 2019 (SB201902015).

\section{Disclosure}

The authors declare that they have no competing interests.

\section{References}

1. Gordic S, Corcuera-Solano I, Stueck A, et al. Evaluation of HCC response to locoregional therapy: validation of MRI-based response criteria versus explant pathology. J Hepatol. 2017;67(6):1213-1221. doi:10.1016/j.jhep.2017.07.030

2. O'Leary C, Mahler M, Soulen MC. Curative-intent therapies in localized hepatocellular carcinoma. Curr Treat Options Oncol. 2020;21 (4):31. doi:10.1007/s11864-020-0725-3

3. Zhou J, Sun HC, Wang Z, et al. Guidelines for diagnosis and treatment of primary liver cancer in China (2017 Edition). Liver Cancer. 2018;7 (3):235-260. doi: $10.1159 / 000488035$

4. Xu Z, Xie H, Zhou L, et al. The combination strategy of transarterial chemoembolization and radiofrequency ablation or microwave ablation against hepatocellular carcinoma. Anal Cell Pathol (Amst). 2019;2019:8619096. doi:10.1155/2019/8619096

5. Park MH, Rhim H, Kim YS, et al. Spectrum of CT findings after radiofrequency ablation of hepatic tumors. Radiographics. 2008;28 (2):379-90, 390-2. doi:10.1148/rg.282075038 
6. Hoffmann R, Rempp H, Kessler DE, et al. MR-guided microwave ablation in hepatic tumours: initial results in clinical routine. Eur Radiol. 2017;27(4):1467-1476. doi:10.1007/s00330-016-4517-x

7. Dong J, Geng X, Yang Y, et al. Dynamic imaging and pathological changes in pig liver after MR-guided microwave ablation. $B M C$ Cancer. 2018;18(1):397. doi:10.1186/s12885-018-4157-4

8. Weiss J, Winkelmann MT, Gohla G, et al. MR-guided microwave ablation in hepatic malignancies: clinical experiences from 50 procedures. Int J Hyperthermia. 2020;37(1):349-355. doi:10.1080/ 02656736.2020 .1750713

9. Yu NC, Chaudhari V, Raman SS, et al. CT and MRI improve detection of hepatocellular carcinoma, compared with ultrasound alone, in patients with cirrhosis. Clin Gastroenterol Hepatol. 2011;9 (2):161-167. doi:10.1016/j.cgh.2010.09.017

10. Clasen S, Rempp H, Hoffmann R, et al. Image-guided radiofrequency ablation of hepatocellular carcinoma (HCC): is MR guidance more effective than CT guidance? Eur J Radiol. 2014;83(1):111-116. doi:10.1016/j.ejrad.2013.09.018

11. Rempp H, Waibel L, Hoffmann R, et al. MR-guided radiofrequency ablation using a wide-bore 1.5-T MR system: clinical results of 213 treated liver lesions. Eur Radiol. 2012;22(9):1972-1982. doi:10.1007/s00330-012-2438-x

12. Kudo M. Radiofrequency ablation for hepatocellular carcinoma: updated review in 2010. Oncology. 2010;78(Suppl 1):113-124. doi:10.1159/000315239

13. $\mathrm{Ng} \mathrm{KK}$, Poon RT, Lo CM, et al. Analysis of recurrence pattern and its influence on survival outcome after radiofrequency ablation of hepatocellular carcinoma. J Gastrointest Surg. 2008;12(1):183-191. doi:10.1007/s11605-007-0276-y
14. Facciorusso A, Del PV, Antonino M, et al. Post-recurrence survival in hepatocellular carcinoma after percutaneous radiofrequency ablation. Dig Liver Dis. 2014;46(11):1014-1019. doi:10.1016/j. dld.2014.07.012

15. Morikawa S, Inubushi T, Kurumi Y, et al. MR-guided microwave thermocoagulation therapy of liver tumors: initial clinical experiences using a 0.5 T open MR system. J Magn Reson Imaging. 2002;16 (5):576-583. doi:10.1002/jmri.10198

16. Clasen S, Pereira PL. Magnetic resonance guidance for radiofrequency ablation of liver tumors. J Magn Reson Imaging. 2008;27 (2):421-433. doi:10.1002/jmri.21264

17. Jia ZY, Chen QF, Yang ZQ, et al. Early assessment of coagulation necrosis after hepatic microwave ablation: a comparison of non-enhanced and enhanced T1-weighted images. Abdom Radiol (NY). 2017;42(6):1781-1787. doi:10.1007/s00261-017-1064-0

18. Chen J, Lin Z, Lin Q, et al. Percutaneous radiofrequency ablation for small hepatocellular carcinoma in hepatic dome under MR-guidance: clinical safety and efficacy. Int J Hyperthermia. 2020;37(1):192-201. doi:10.1080/02656736.2020.1728397

19. Weiss J, Hoffmann R, Rempp H, et al. Feasibility, efficacy, and safety of percutaneous MR-guided ablation of small $(</=12 \mathrm{~mm})$ hepatic malignancies. J Magn Reson Imaging. 2019;49(2):374-381. doi:10.1002/ jmri.26252

\section{Publish your work in this journal}

Cancer Management and Research is an international, peer-reviewed open access journal focusing on cancer research and the optimal use of preventative and integrated treatment interventions to achieve improved outcomes, enhanced survival and quality of life for the cancer patient.
The manuscript management system is completely online and includes a very quick and fair peer-review system, which is all easy to use. Visit http://www.dovepress.com/testimonials.php to read real quotes from published authors. 